\title{
O DECLÍNIO DO PT? O PANORAMA DOS FILIADOS DO PARTIDO NO ESTADO DO RIO DE JANEIRO
}

\author{
Philippe Chaves Guedon ${ }^{1}$
}

\section{RESUMO}

O presente artigo trabalha com o panorama de filiação ao Partido dos Trabalhadores (PT) no estado do Rio de Janeiro no período de 2011-2016. Assim, dialoga com a literatura recente sobre partidos políticos e a escassa produção específica sobre filiação partidária. A questão do artigo é, além da construção do panorama, testar se o período crítico vivido pelo partido afetou os incentivos a participação na estrutura organizacional a partir dos impulsos de filiação ou desfiliação. Para tal, utiliza os dados do Tribunal Superior Eleitoral nesses anos. Nos resultados, observa que a filiação segue estável em relação ao quadro associativo geral, apesar do número crescente de pedidos de desfiliação. O número de filiados ao partido no estado não sofre, portanto, alterações significativas. Ao fim, constata que os ex-filiados do PT tendem a realocar-se em outras legendas do sistema partidário, em detrimento de deixar de participar da política partidária, com maior presença em outras agremiações de esquerda.

Palavras-chave: filiados, partidos políticos, partido dos trabalhadores, sistema partidário.

\section{THE DECLINE OF WORKERS PARTY (PT)? THE FRAMEWORK OF AFFILIATION OF THE PARTY IN THE STATE OF RIO DE JANEIRO}

\begin{abstract}
The article tackles the affiliation framework of the Workers Party (PT) in the state of Rio de Janeiro, between 2011 and 2016. This way, it dialogues with the recent literature on political parties and the scarce production of specific literature on party affiliation. The issue presented by the article is not only the construction of the framework, but also testing if the critical period experienced by the party has affected incentives to participate within the organizational structure stemming from the impulses of affiliation or exclusion. In order to do that, data from the Supreme Electoral Court (TSE) has been used over the years. When looking at the results, it is observed that affiliation remains stable in relation to the general board of association, in spite of the increase in the number of exclusion
\end{abstract}

${ }^{1}$ Bolsista de Mestrado da CAPES/CNPQ. Mestrando em História, Política e Bens Culturais no PPHPBC/CPDOC/FGV. Bacharel em Ciência Política pela Universidade Federal do Estado do Rio de Janeiro. E-mail: philippe.guedon@fgv.br 
requests. Therefore, the number of party affiliates does not suffer significant alternations. In conclusion, it is noted that PT's ex-affiliates tend to reallocate to other groupings within the political party system, in detriment of losing the opportunity to participate in party politics, obtaining a greater presence in leftist groupings.

Keywords: affiliates, polititcal parties, workers party, party system.

\section{Introdução}

Segundo índice calculado pelo IBOPE sobre a confiança nas instituições (ICS)², os partidos políticos estão em penúltimo lugar dentre as vinte instituições citadas. Está à frente apenas da instituição da presidência da república. Esse dado poderia ser indicativo de questionamentos acerca das instituições representativas. Por outro lado, o Brasil possui filiações partidárias próximas ou maiores do que democracias tidas como referências a instituições fortes, como a Alemanha e França (Speck, 2013).

Dessa forma, o caso brasileiro inspira maior atenção aos estudos de partidos políticos enquanto organizações, uma vez que já se constituiu forte arcabouço teórico e metodológico sobre os partidos nas arenas governativa e legislativa. Na arena organizacional, são recentes os trabalhos sobre as organizações intrapartidárias e também sobre os processos endógenos aos partidos políticos, como o recrutamento. Dentro desse campo, os filiados compõe importante chave de interpretação sobre a vida participativa, cultura política e funcionamento interno dos partidos, conquanto seja pouco trabalhado na literatura especializada da área.

Uma das justificativas possíveis para os poucos trabalhos sobre o tema é a dificuldade metodológica. Os dados administrativos do Tribunal Superior Eleitoral apresentam maior consistência apenas a partir do cadastramento dos filiados no sistema "filiaweb", a partir de 2009, que permitiu informações atualizadas sobre a filiação e desfiliação dos eleitores (Speck, 2013). Outras formas de incursão como os surveys são de difícil financiamento, bem como não há cadastro público

2 Índice calculado pelo Ibope desde 2009, sempre no mês de julho. Foi realizado a partir de pesquisa com 2002 pessoas a partir de 16 anos, em 142 municípios do país. Este relatório acessado diz respeito à pesquisa de 2017: http://www.ibopeinteligencia.com/noticias-e-pesquisas/confianca-no-presidentegoverno-federal-e-congresso-nacional-e-a-menor-em-9-anos/ (Acessado em 04/08/2017). 
de informações dos filiados que possibilitem encontra-lo.

Sobre esse terreno, de incursão recente, tem-se o presente trabalho de caráter exploratório sobre o panorama da filiação do Partido dos Trabalhadores (PT) no estado do Rio de Janeiro.

O período de análise se inscreve desde o ano de 2011, reeleição de Dilma Rousseff, até o ano de 2016, que se relaciona com a saída do partido no cargo da presidência do país. $\bigcirc$ trabalho discute as filiações, desfiliações, os motivos de desfiliação e os caminhos dos desfiliados, se estes vão para novas legendas ou decidem por não participar mais enquanto filiados de partidos políticos.

Como fonte o trabalho utiliza os dados do Tribunal Superior Eleitoral, referenciados também nos estudos de Speck (2013). Os dados foram trabalhados no programa estatístico "R", que possibilitou o tratamento das informações e, por fim, o cruzamento dos números de registros dos filiados para observar o fluxo de filiados do PT para outras legendas. ${ }^{3}$

O trabalho, apesar de panorâmico, tem como hipótese que a saída do partido do cargo à nível federal, bem como a perda de força enquanto grupo de poder nas últimas eleições se traduziria em perda, também, de filiados. Dentro desse universo de ex-filiados, alguns poderiam migrar para novas legendas e outros poderiam optar pela saída do quadro de participação político-partidária. Assim, testa-se se a perda de filiados do partido respondeu também ao incentivo de fragmentação do sistema partidário brasileiro, principalmente a partir de 2011 com a criação de seis novas legendas (PSD, SD, PROS, REDE, NOVO e PMB).

No mais, busca preencher a lacuna de estudos de caso de dinâmicas locais específicas, como no estado do Rio de Janeiro, e iluminar o panorama dos filiados de maneira geral, como esforço inicial de uma agenda de estudos que, desde já, se mostra profícua.

Dessa forma, o trabalho está estruturado da seguinte forma, além desta introdução: (i) discussão teórica sobre os partidos políticos no Brasil e a recente incursão nos filiados; (ii) análise dos dados sobre os filiados ao Partido dos Trabalhadores; (iii) considerações finais e possíveis futuras incursões.

\section{Discussão teórica: a institucionalidade e os estudos sobre partidos políticos}

${ }^{3}$ No tratamento dos dados foram retirados 8646 que continham inconsistência em informações de filiação ou desfiliação; assim, o universo total trabalhado foi de 1.377.607 filiados. 
Nos anos 90, a recente redemocratização e a articulação de novos atores na arena política ensejaram diversos trabalhos acerca da relação entre os partidos políticos e a sociedade brasileira. Nesse período, as análises foram críticas quanto à institucionalização dos partidos e sua relevância frente ao desenho institucional e a realidade local.

Assim, as características institucionais do sistema político brasileiro como o multipartidarismo, o voto proporcional de lista aberta e o federalismo foram caracterizadas como entraves ao funcionamento da democracia no país (Mainwaring, 1999; Ames, 2003). A lógica do voto proporcional incentivaria a fragmentação partidária, que, por sua vez, diminuiria a eficiência do processo legislativo (Ames, 2003). Além disso, os partidos seriam pouco determinantes na dimensão eleitoral (Ames, 1995; Samuels, 1997).

De todo modo, a interpretação corrente é de que o desenho institucional brasileiro acarretaria dificuldades de governabilidade e de identificação do eleitor para com um partido político. No entanto, em resposta a essa abordagem crítica, autores observaram que os incentivos da arena eleitoral não seriam transpostos, de igual modo, as arenas governativas e legislativas.

O ponto de inflexão nessa interpretação foi a publicação de Figueiredo e Limongi (1998). Os autores identificaram que a estrutura de funcionamento do congresso brasileiro não é atomizada, mas concentrada nas lideranças partidárias, figuras de força estruturante do trabalho legislativo. Além disso, observou que o executivo tinha ampla capacidade de aprovação de proposta e gestão orçamentária, que afetariam e incentivaram comportamentos específicos dentro da arena legislativa, tal como a cooperação entre o executivo e os parlamentares. Nessa agenda de interpretação sobre a relação executivo-legislativo seguiram diversos trabalhos demonstrando o peso dos partidos na relação e na estruturação desse campo (Pereira e Mueller, 2003; Amorim Neto, 2002; Santos, 1997).

$\mathrm{Na}$ arena organizativa, Braga (2008) argumenta que os estudos foram relegados ao segundo plano, uma vez que a interpretação corrente de fragilidade dos partidos deslegitimava a atenção detida nesses atores. Os partidos eram tidos como pouco institucionalizados e incapazes de impedir a autonomização dos políticos frente a organização. No entanto, também com a interpretação mais detida aos processos internos e rejeitando a transposição de incentivos entre as arenas - como da arena eleitoral para a organizativa, iniciou-se agenda sobre o recrutamento partidário.

De início, esses trabalhos sobre recrutamento trabalharam com a ideia 
daqueles que "chegaram lá", ou seja, identificavam a interação entre perfil do candidato e do partido a partir apenas dos eleitos (Perissinotto e Miríade, 2009).

São referências nesse tipo de abordagem Marenco dos Santos (1997) analisando a composição da Câmara dos Deputados em 1946-62 e 1986-1994; bem como Rodrigues (2002) analisando a bancada do PPB, PFL, PMDB, PSDB, PDT e PT na legislatura a partir de 1998. No primeiro trabalho, conclui que a representação não é um campo fechado a profissionalização, com espaço para a emergência de atores oriundos de outras esferas de vida social. Já no segundo, identifica que o perfil dos eleitos varia de partido para partido, o que evidencia que os partidos teriam celeiros diferentes de recrutamento a depender da sua posição ideológica.

Em passo posterior, alguns autores afirmaram que não seria possível constituir todo o processo de recrutamento apenas observando os indivíduos que tiveram o sucesso eleitoral. Desse modo, Bolognesi (2009) observa a composição social dos candidatos do PT e do DEM para deputado federal. Conclui que existe orientação dos partidos quanto à seleção de candidatos mais afeitos ao posicionamento ideológico. Em exemplo, trabalhadores da área de educação estavam mais no Partido dos Trabalhadores, enquanto profissionais liberais mais presentes no DEM.

Além da simples seleção de candidaturas afeitas ao posicionamento ideológico, os partidos ainda deteriam capacidade de influenciar o sucesso eleitoral de determinado candidato com a distribuição de recursos como o Fundo Partidário e o Horário Eleitoral Gratuito (Braga, Veiga e Miríade, 2009).

Assim, é possível observar que a trajetória da produção especializada brasileira foi de responder as críticas quanto à institucionalização do sistema partidário e eleitoral, olhando a partir de arenas específicas de atuação dos partidos políticos. Nessa última, organizativa, os trabalhos detiveram na fase final da conformação da trajetória do indivíduo dentro do partido, como a seleção de candidaturas ou o incentivo a esses perfis.

O balanço da literatura sobre esse tipo de abordagem, na arena organizativa, é realizado por Peres e Machado (2017). Segundo eles, estudou-se os processos finais do recrutamento partidário, como a seleção de candidaturas e o incentivo de determinadas características sociais de candidatos em detrimento de outras. No entanto, pouco observou as etapas inicias desse processo, como a filiação e a formação de quadros dentro dos partidos políticos.

À despeito da pouca produção, os filiados são de crucial importância para 
a sobrevivência dos partidos, uma vez que agregam um valor simbólico a sua existência, bem como são recursos humanos fundamentais para assegurar o funcionamento rotineiro, garantir a passagem das ideias centrais da agremiação, mobilizar recursos e apoio e, também, garantir a renovação dos quadros partidários (Lisi, 2015).

No Brasil, os dados de filiação demonstram certa relevância dos partidos políticos. Se em países europeus considerados desenvolvidos a média de filiação flutua entre 5 e 15\% (Biezen, Mair e Pogundke, 2011), no Brasil a média de filiação em 2016 era de 11,6\%4 em relação ao número total de eleitores.

Essa relevância foi testada por Speck, Braga e Costa (2015), a partir do Estudo Eleitoral Brasileiro, para observar se a filiação seria um ato desprovido de significado ou indicaria alguma vinculação do indivíduo para com o partido político. Ao cruzarem as respostas de preferência partidária e filiação, identificaram que 50,2\% dos filiados tem identificação partidária congruente (dizem gostar mais do partido que é filiado). Esse resultado varia conforme identificação ideológica, sendo os filiados de esquerda mais congruentes que os de direita. Os autores realizam uma regressão logística para observar a diferença entre os grupos dos filiados e não filiados. Nela, observam que os os dois grupos possui atitudes diferentes como maiores indicadores de associativismo, ativismo e maior possibilidade de votar no partidos nos filiados. Corrobora, assim, a argumentação de que a filiação é provida de algum sentido, uma vez que, em síntese, se fosse um ato desprovido de significado, as atitudes dos filiados e não filiados seriam próximas, o que não são, segundo os autores.

No final do artigo, indica que são necessárias pesquisas mais detidas aos próprios filiados, com surveys e outros métodos que identifiquem motivações na filiação. Um passo nesse sentido é o trabalho de Amaral (2014), que investiga o PT, PSDB, PSB, PR, DEM, PTB, PPS, PMDB, PP e PDT no estado de São Paulo a partir dos seus filiados. ${ }^{5}$ Como resultado, encontra que os motivos para filiação mais expressivos para "convicções políticas" estão no PT (61,9\%) e PSDB (43,1\%); enquanto a motivação de "carreira política" é mais presente no PR (15,2\%) e PDT (17,6\%). É possível observar assim que os incentivos a filiação variam de legenda

${ }^{4}$ Dados do Tribunal Superior Eleitoral referenciados em reportagem publicada em: <http://infograficos. oglobo.globo.com/brasil/filiacao-partidaria-no-brasil.html> (Acessado em 14/06/2017).

${ }^{5} \mathrm{O}$ autor reconhece viés na pesquisa, uma vez que as entrevistas foram realizadas nas proximidades dos diretórios municipais dos partidos políticos. Assim, tiveram acesso aos filiados de média/alta intensidade, que frequentaram a sede do partido. 
para legenda.

Outro tipo de proposição buscando identificar motivações sobre filiação está em Speck (2013). O autor trabalha com os registros administrativos do TSE para observar se as filiações seriam idealistas ou oportunistas. $\bigcirc$ primeiro grupo, dos idealistas, seriam aqueles se filiariam a um determinado partido político em contexto pré-eleitoral; enquanto o segundo seria classificado como oportunista, se ocorresse em momento pós-eleitoral, uma vez que significaria que o indivíduo buscaria benesses da organização partidária. Ao fazer o que chama de "cardiograma da filiação" observa que o grande número das filiações não deriva desses dois momentos, mas sim nos primeiros anos eleitorais, principalmente nas eleições municipais. Isso indicaria que o lançamento de candidaturas ou o apoio a determinada candidatura impulsionaria a filiação partidária. De todo modo, é um achado a partir de dados apenas de filiação, que pode ser complementado com outras pesquisas, com incentivos ao método qualitativo para observar as motivações.

Como se demonstrou, a literatura majoritária na Ciência Política brasileira institucionalista da redemocratização dialogou com as críticas quanto a baixa institucionalização do sistema político nacional. Esforços recentes demonstram que são fortes na estruturação dos trabalhos legislativos, estruturam o processo eleitoral e ainda são vitais a partir do prisma organizativo, como representantes da sociedade civil e canal único de participação do jogo político institucional.

Sobre os filiados, os trabalhos ainda carecem de sistematização, tendo como característica maior o caráter exploratório. Ainda assim, já apontam que os partidos não são indiferenciados na relação entre indivíduo e estrutura.

\section{Análise de dados: o panorama de filiações ao PT}

Nesse terreno apontamos para o estudo dos dados de filiados do Partido dos Trabalhadores no Rio de Janeiro. A hipótese que orienta o trabalho é de que o momento crítico vivido pelo partido afetaria o envolvimento dos indivíduos e a organização partidária, o que poderia ser observado nos filiados.

Assim, para entender o panorama geral de filiação ao PT, faz-se necessário observar o plano mais abrangente de filiação total no estado. 
Gráfico 1 - Total de filiados aos partidos políticos no estado do Rio de Janeiro (mês de dezembro como referência)

\begin{tabular}{|llllll|}
\hline 1081664 & 1067770 & 1081664 & 1079135 & 1102148 & 1130748 \\
\hline 2011 & 2012 & 2013 & 2014 & 2015 & 2016 \\
\hline
\end{tabular}

Fonte: Tribunal Superior Eleitoral - Elaboração do autor

Enquanto a literatura internacional afirma que os vínculos entre a sociedade civil e os partidos políticos estão mais escassos (Manin, 2013) e que é tendência que os partidos estejam perdendo filiados nas maiores democracias do mundo (Biezen, Mair e Poguntke, 2012), os dados administrativos do TSE apontam em outra direção. No panorama estadual, há uma estabilização do número filiados e aumentos sucessivos, como em 2015 e 2016. Não é de interesse do presente artigo afirmar que o Brasil caminha no sentido contrário das tendências internacionais, até porque os registros administrativos não permitem maiores inferências ${ }^{6}$, mas é interessante notar que o sistema está estruturado com alguma participação dos eleitores dentro da estrutura político partidária.

Em relação especificamente ao Partido dos Trabalhadores, é intuitivo pensar que havia mais incentivos a participação político partidária no período em que ocupava o executivo federal. Da mesma forma, a saída em 2016 com o processo de impeachment poderia indicar caminhos de menor incentivo. No entanto, ao analisarmos os dados identificamos que há uma manutenção do número de filiados com pouca variação de tendência no período. A participação dos filiados ao PT dentro do número do total de filiados é, ainda, crescente desde 2014 (2014 - 8,82; $2015-8,99 ; 2016-9,29)$.

6 Para trabalhar com a ideia de vínculo entre os partidos e os eleitores/filiados deve-se recorrer a outras estratégias, como surveys ou pesquisas qualitativas. A análise dos registros administrativos apenas permite construir o panorama macro da filiação partidária. 
O declínio do PT?, pp. 154 - 169

Gráfico 2 - Filiados ao PT no Rio de Janeiro (mês de dezembro como referência)

$\begin{array}{lllll}121,335 & 119,421 & 121,335 & 122,417 & 122,003\end{array}$

\begin{tabular}{llllll}
\hline 2011 & 2012 & 2013 & 2014 & 2015 & 2016
\end{tabular}

Fonte: Tribunal Superior Eleitoral - Elaboração do autor

A perda de filiados do partido é ainda mais mitigada se compararmos com a perda de outros partidos de importância significativa. No gráfico abaixo consta a participação relativa dos dez maiores partidos ${ }^{7}$ no total da filiação no estado do Rio:

Gráfico 3 - Participação relativa dos dez maiores partidos no total de filiados do estado (mês de dezembro como referência)

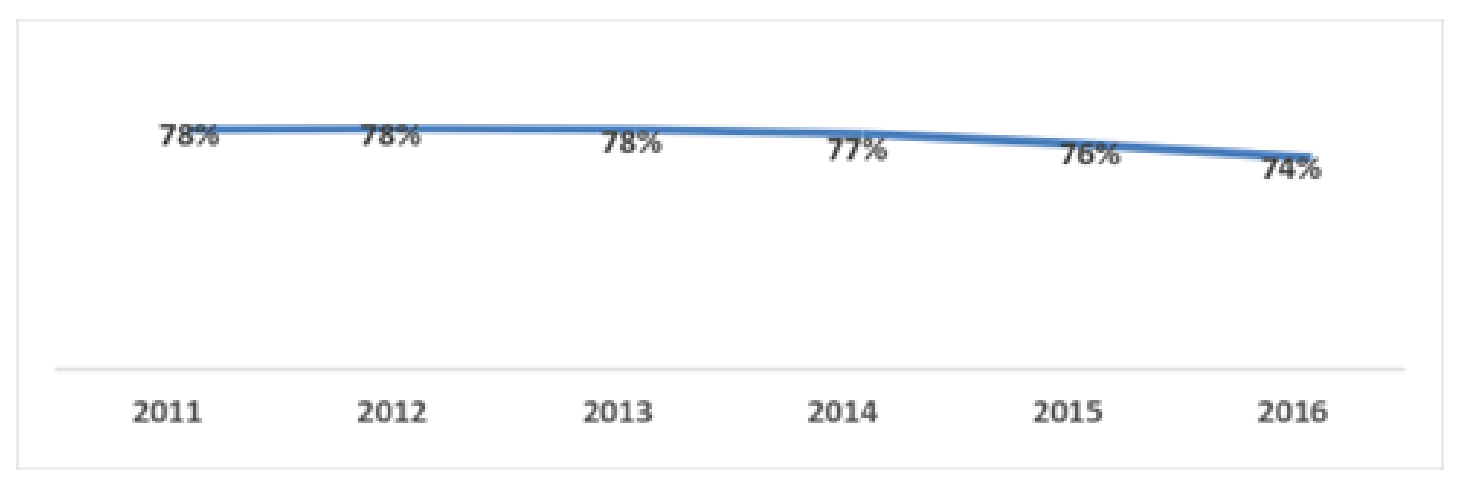

Fonte: Tribunal Superior Eleitoral - Elaboração do autor

Os dados acima refletem a fragmentação do sistema partidário a partir da filiação. Se os dados de filiação demonstram estabilidade e os partidos maiores perdem força, é possível notar o crescimento de legendas menores. A criação

${ }^{7}$ Os dez maiores partidos em relação ao número de filiados são: DEM, PCdoB, PDT, PMDB, PP, PR, PSB, PSDB, PT e PTB.

CSOnline - Revista Eletrônica de Ciências Sociais, Juiz de Fora, n. 27 (2018) 
de novos partidos a partir de 2011 como REDE, SD, PSD, NOVO e PMB são incentivos à fragmentação também no universo da associação partidária.

Umavezque o impulso no partido dos trabalhadores nãoéde perdaconsiderável de seus filiados, também não há movimento de renovação em larga medida. Os dados abaixo demonstram que o ano de 2011 foi o ano de maior pico de filiação dentre os analisados. No entanto, não é pretensão desse artigo indicar a razão para esse crescimento. Indicativos podem ser a chegada de Dilma Rouseff ao executivo federal, a alta popularidade de Lula ou circunstâncias de nível local, mas todas devem ser testadas em trabalhos com atenção detida apenas a este fenômeno. No mais, desde 2013 as filiações são baixas se comparadas as outras legendas.

Gráfico 4 - Novas filiações ao PT nos anos (2011-2016)

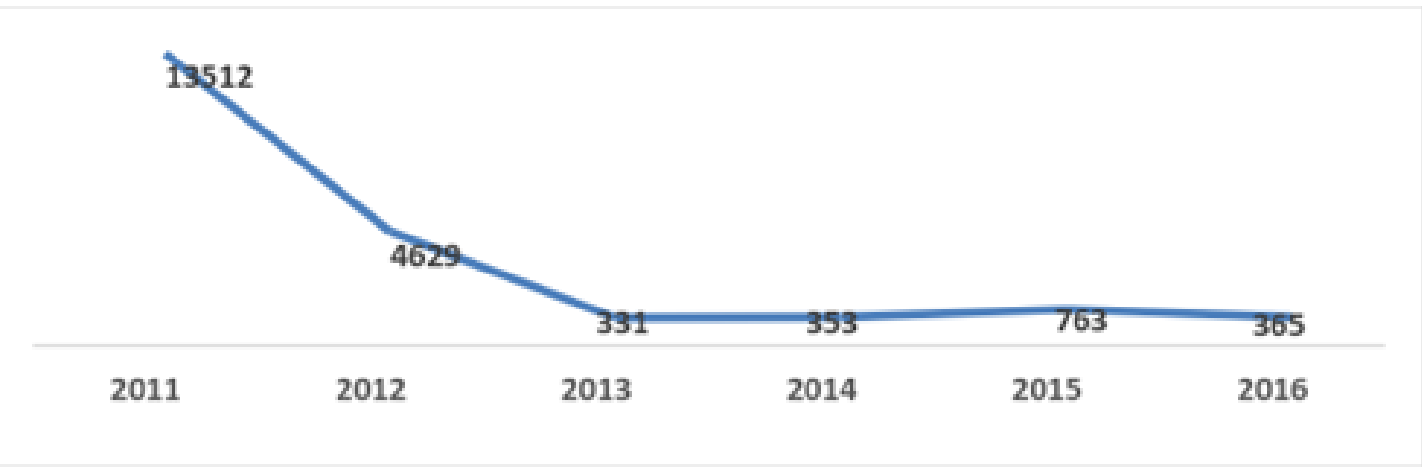

Fonte: Tribunal Superior Eleitoral - Elaboração do autor

Como já demonstrado, não houve tendência de perda de filiados no partido. Tampouco de renovação. Não pretendemos argumentar que isso indica que o partido mantém as mesmas bases do que tivera antes. Os dados não permitem tal conclusão. São comuns os casos de filiados de baixa participação. Além disso, não há regra para recadastramento periódico dos filiados e os custos de desfiliação - comunicar ao diretório municipal de forma escrita em três vias e encaminhar ao Cartório Eleitoral - são tidos como altos, uma vez que manter-se filiados não acarreta custos ao eleitor.

Ainda assim, houveram eleitores que tiveram esse impulso de desfiliação. No cadastro de filiados do TSE há um campo que indica a situação do filiado, podendo ser: regular, com erro, sub judice, desfiliado e cancelado. Trabalharemos, portanto, com os dois últimos para verificar, ainda que de maneira parcial o 
motivo da desfiliação. Todos os que constam como "cancelados" apresentam alguma justificativa para tal, como decisão judicial, cancelamento automático, a pedido do partido e a pedido do eleitor.

Gráfico 5 - Percentual por tipo de cada tipo de cancelamento

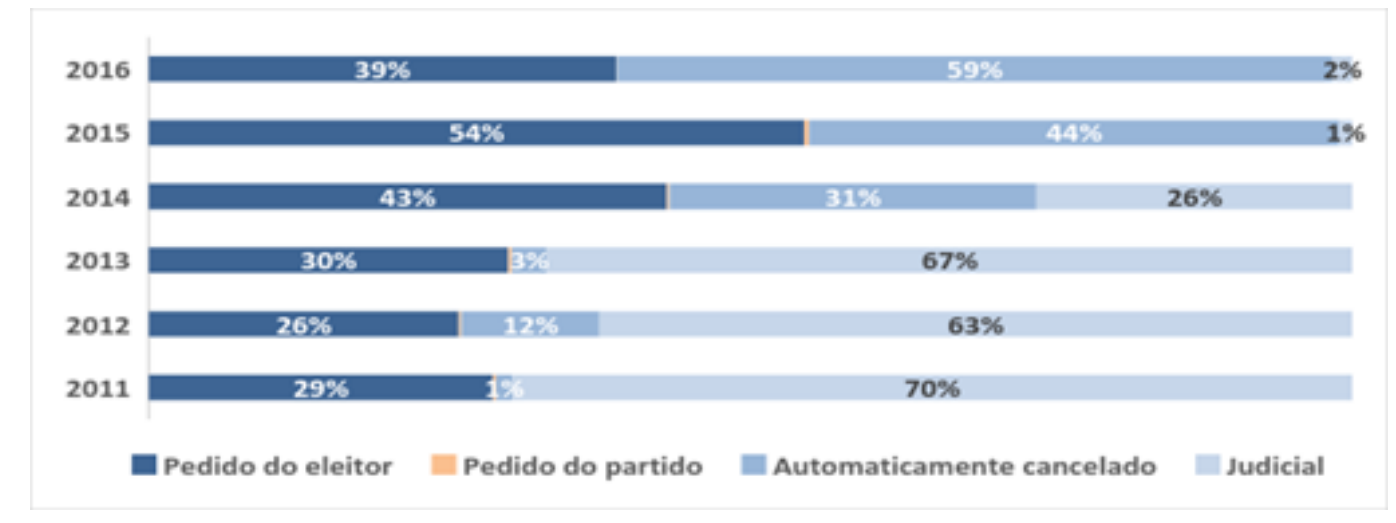

Dados do Tribunal Superior Eleitoral - Elaboração do autor

Interessante neste ponto é o aumento de pedidos de desfiliação a pedido do eleitor. Com maior presença no ano de 2015, mas com significativo aumento já em 2014, indica que houve um incentivo do filiado para não se manter mais dentro da organização partidária.

Os que tiveram cancelamento via judicial diminuem tanto percentualmente quanto em absoluto. Se em 2011 houveram 1775 decisões judiciais, em 2016 foram apenas 26. Os automaticamente cancelados tomam maior proporção a partir de 2014, o que pode indicar maior rigor do Tribunal com os registros de filiação. Eles são automaticamente cancelados quando são constatados erros nas datas de filiação ou quanto possuem dupla filiação a partidos políticos.

Para registrar-se em outro partido é necessário desfiliar-se no primeiro e filiar-se em um segundo. Esse movimento foi seguido por parte dos desfiliados do PT. Identificamos o fluxo de migração dos filiados nesse período para as novas legendas e é possível verificar caminhos majoritários desses filiados que desejam ainda manter-se participando do jogo político-institucional, agora em nova legenda. Foram encontrados 65,5\% desses desfiliados em novas legendas.

Observando o fluxo desses filiados, os partidos de esquerda como PSB, PCdoB, PSOL, PDT são receptáculos significativos desses eleitores. Porém, se considerados em absoluto, o fluxo é maior para partidos de centro-direita. 
Como mostra o fluxo, a gama de legendas que os filiados caminham é variada, contemplando todos os partidos do sistema partidário. As motivações para filiações nas organizações podem ocorrer para além de motivos ideológicos, como a partir de um cálculo pragmático, a partir de laços familiares ou de amizade, bem como das disputas à nível local com diferenças significativas das disputas nacionais. De todo modo, os dados indicam que, de maneira geral, o ex-filiado ao PT busca ainda participar do jogo político-institucional, realocando-se em outras legendas.

Tabela 1 - Distribuição dos ex-filiados do PT

\begin{tabular}{|l|c|c|l|c|}
\hline PSB & $7,1 \%$ & - & REDE & $2,7 \%$ \\
\hline PC do B & $6,8 \%$ & - & PSDC & $2,6 \%$ \\
\hline PSOL & $6,7 \%$ & - & PRTB & $2,6 \%$ \\
\hline PHS & $6,0 \%$ & - & DEM & $2,5 \%$ \\
\hline PDT & $5,6 \%$ & - & PT do B & $2,2 \%$ \\
\hline PMDB & $4,6 \%$ & - & PPL & $2,1 \%$ \\
\hline PSDB & $4,3 \%$ & - & PPS & $2,0 \%$ \\
\hline PR & $4,2 \%$ & - & PRP & $1,7 \%$ \\
\hline PP & $3,6 \%$ & - & PMB & $1,6 \%$ \\
\hline PRB & $3,5 \%$ & - & PSL & $1,4 \%$ \\
\hline PV & $3,5 \%$ & - & PTC & $1,4 \%$ \\
\hline PTB & $3,3 \%$ & - & PMN & $1,0 \%$ \\
\hline PROS & $3,2 \%$ & - & PEN & $1,0 \%$ \\
\hline SD & $3,1 \%$ & - & PSTU & $0,7 \%$ \\
\hline PTN & $2,8 \%$ & - & NOVO & $0,2 \%$ \\
\hline PSD & $2,8 \%$ & - & PCB & $0,2 \%$ \\
\hline PSC & $2,7 \%$ & - & PCO & $0,1 \%$ \\
\hline
\end{tabular}

Fonte: Registros administrativos do TSE sistematizados pelo autor

\section{Considerações finais: conclusões e apontamentos futuros}

Os estudos de partidos políticos no Brasil têm como principal questão a sua própria institucionalização. Há um debate já bem disseminado sobre o seu funcionamento na estruturação dos trabalhos legislativos e na arena eleitoral. Contudo, em outras esferas de atuação, como sua composição organizacional são 
recentes as incursões. Os estudos de recrutamento são os mais disseminados nesse campo, ainda que detidos nas suas últimas etapas, como a seleção de candidatos (Peres e Machado, 2017).

Os filiados são subrepresentados nas análises sobre partidos políticos e o presente trabalho buscou enfrentar essa questão a partir do PT no estado do Rio de Janeiro. Encontrou que o sistema partidário é estável no que diz respeito aos filiados entre 2011-2016. Ao mesmo tempo em que os grandes partidos perdem hegemonia, dada a crescente fragmentação partidária, os pequenos partidos recrutam novos indivíduos para as suas fileiras.

Especificamente no PT, não houve rebatimento negativo efetivo no número de desfiliações no período analisado. Pode ser que a diminuição da entrada de novos filiados seja um indicativo das dificuldades do partido, mas ainda assim mantém estabilidade em relação aos associados.

Em relação aos filiados que decidiram se desfiliar, no período, a causa "a pedido do eleitor" aumenta consideravelmente a partir de 2014. Nesse ponto, é importante ressaltar que no Brasil não existem custos de manter-se filiado, portanto, são comuns os casos de indivíduos que abandonam a participação político-partidária, ou a tem de maneira lateral mas não registram o seu cancelamento. De todo modo, o número crescente de desfiliações pedidas a partir do eleitor indica algum desgaste em relação aos seus antigos apoiadores.

Além disso, observa que dentre os desfiliados existem muitos que se realocaram em outras legendas, mais de 3/5. No geral, os partidos com maiores percentuais são de alguma proximidade ideológica. No entanto, em absoluto, a filiação não esgota as explicações para filiar a um novo partido.

No mais, o presente trabalho buscou abrir caminhos para estudos detidos as organizações partidárias a partir desses atores vitais para entender cultura política e participação: os filiados. Dessa forma, incentiva incursões qualitativas nas razões para a filiação e desfiliação, como estudos sistemáticos que permitam compreender os sentidos de alta presença de filiados nos partidos políticos a despeito da opinião corrente de sua incapacidade de conduzir as demandas sociais.

\section{Bibliografia:}

AMARAL, Oswaldo. Ainda conectado: o PT e seus vínculos com a sociedade. 
Opinião Pública, Campinas, v. 17, n. 1, p. 1-44, 2011.

AMARAL, Oswaldo. Por dentro das bases partidárias: uma análise do perfil dos filiados a partidos políticos no estado de São Paulo. Paper preparado para apresentação no Instituto de Iberoamérica, Universidad de Salamanca, 2014.

AMES, Barry. Electoral strategy under open-list proportional representation. American Journal of Political Science, p. 406-433, 1995.

AMES, Barry. Entraves da Democracia no Brasil. Rio de Janeiro. Fundação Getulio Vargas Editora, 2003.

AMORIM NETO, Octavio. "Presidential Cabinets, Electoral Cycles, and Coalition Discipline in Brazil", in S. Morgenstern e B. Nacif (eds.), Legislative Politics in Latin America. Cambridge, Cambridge University Press, pp. 48-78, 2002.

BIEZEN, I; MAIR, P. e POGUNGTKE, T. Going, going...gone? The decline of party membership in contemporary Europe. European Journal of Political Research, 51(1), pp.24-56, 2012.

BOLOGNESI, Bruno. Candidatos e Eleitos: o recrutamento político nos partidos paranaenses nas eleições 2006. Dissertação apresentada ao Programa de Pós-Graduação em Sociologia na Universidade Federal do Paraná, 2009.

BOLOGNESI, Bruno. A seleção de candidaturas no DEM, PMDB, PSDB e PT nas eleições legislativas federais brasileiras de 2010: percepções dos candidatos sobre a formação das listas. Revista de Sociologia e Política, 21(46), pp.45-68.201,

BRAGA, Maria do Socorro Sousa. Organizações Partidárias e Seleção de Candidatos no estado de São Paulo. Opinião Pública (UNICAMP. Impresso), v. 14, p. 454-486, 2008.

BRAGA, Maria do Socorro Sousa; VEIGA, Luciana Fernandes; MIRIADE, Angel. Recrutamento e perfil dos candidatos e dos eleitos à Câmara dos Deputados nas eleições de 2006. Rev. bras. Ci. Soc., São Paulo, v. 24, n. 70, p. 123-142, 
2009.

CARREIRAO, Yan de Souza; KINZO, Maria D’Alva G. Partidos políticos, preferência partidária e decisão eleitoral no Brasil (1989/2002). Dados, Rio de Janeiro, v. 47, n. 1, p. 131-167, 2004.

FIGUEIREDO, Argelina.; LIMONGI, Fernando. Bases institucionais do presidencialismo de coalizão. Lua Nova, v. 44, p. 81-106, 1998.

LISI, Marco. Democracia intra-partidária, filiados e elites intermédias: o caso do Partido Socialista português. Análise Social, 214, I (1.), 2015.

MAINWARING, Scott. Rethinking Party Systems in the Third Wave of Democratization: The case of Brazil. Stanford : Stanford University, 1999.

MANIN, Bernard. A democracia do público reconsiderada. Novos Estudos CEBRAP. São Paulo, n.97, pp. 115-127, 2013.

MARENCO DOS SANTOS, André. Nas fronteiras do campo político: Raposas e outsiders no Congresso Nacional. Revista Brasileira de Ciências Sociais, 12(33), pp.87-101, 1997.

PEREIRA, Carlos; MUELLER, Bernardo. Partidos fracos na arena eleitoral e partidos fortes na arena legislativa: a conexão eleitoral no Brasil. Dados, Rio de Janeiro, v. 46, n. 4, p. 735-771, 2003.

PERES, Paulo e MACHADO, Amanda. Uma tipologia do recrutamento partidário. Opin. Publica [online]. vol.23, n.1, pp.126-167, 2017

PERISSINOTTO, Renato e Miríade, Angel. Caminhos para o Parlamento: Candidatos e Eleitos nas Eleições para Deputado Federal em 2006. DADOS Revista de Ciências Sociais, Rio de Janeiro, Vol. 52, no 2, 2009.

RODRIGUES, Leôncio Martins. Partidos, ideologia e composição social: Partidos, ideologia e composição social. Rev. bras. Ci. Soc., São Paulo, v. 17, n. 48, p. 31-47, 2002. 
SAMUELS, David. Determinantes do Voto Partidário em Sistemas Eleitorais Centrados no Candidato: Evidências sobre o Brasil. Dados [online], vol.40, n.3, 1997.

SANTOS, Maria Helena de Castro. Governabilidade, governança e democracia: criação da capacidade governativa e relações Executivo-Legislativo no Brasil pós-constituinte. DADOS, v. 40, n. 3, Rio de Janeiro, 1997.

SPECK, Bruno W. Nem ideológica, nem oportunista: A filiação partidária no contexto pré-eleitoral no Brasil. Cadernos Adenauer, v. 14, n. 2, p. 37-60, 2013.

SPECK, Bruna ; BRAGA, Maria do Socorro.; COSTA, Valeriano. Estudo exploratório sobre filiação e identificação partidária no Brasil. Revista de Sociologia e Política, vol. 23, n 56, p. 125-148, 2015. 